\title{
Photodiagnosis and Photodynamic Therapy \\ METHYL AMINOLEVULINATE PHOTODYNAMIC THERAPY AFTER PARTIAL DEBULKING IN THE TREAMENT OF SUPERFICIAL AND NODULAR BASAL CELL CARCINOMA: 3-YEARS FOLLOW-UP. --Manuscript Draft--
}

\begin{tabular}{|c|c|}
\hline Manuscript Number: & PDPDT-D-20-00670R1 \\
\hline Article Type: & Research Paper \\
\hline Keywords: & $\begin{array}{l}\text { Photodynamic therapy; methyl aminolevulinate; superficial basal cell carcinoma; } \\
\text { nodular basal cell carcinoma. }\end{array}$ \\
\hline Corresponding Author: & $\begin{array}{l}\text { Clara Gómez } \\
\text { Consejo Superior de Investigaciones Científicas } \\
\text { Madrid, Spain }\end{array}$ \\
\hline First Author: & Clara Gómez \\
\hline \multirow[t]{3}{*}{ Order of Authors: } & Clara Gómez \\
\hline & Pilar Cobos, Ph.D. \\
\hline & Enrique Alberdi, Dr \\
\hline Abstract: & $\begin{array}{l}\text { Background: The recently reported increase in the number of basal cell carcinoma } \\
\text { (BCC) lesions has prompted the use of minimally invasive therapies. Photodynamic } \\
\text { therapy (PDT) is considered to be a good treatment option. The objective of the } \\
\text { present work was to analyze the efficacy of methyl aminolevulinate - mediated } \\
\text { photodynamic therapy (MAL-PDT) in patients suffering from superficial or nodular } \\
\text { BCCs. } \\
\text { Methods: A total of } 220 \text { BCC lesions ( } 76 \text { superficial and } 144 \text { nodular), clinically } \\
\text { diagnosed and confirmed by histopathology analysis, were treated in } 174 \text { patients } \\
\text { (mean age } 72.5 \text { ). Debulking using curettage was performed before two or three MAL- } \\
\text { PDT sessions ( } \lambda=630 \mathrm{~nm} \text {; } 90 \mathrm{~J} / \mathrm{cm} 2 ; 23 \text { min) at } 4 \text {-week intervals. Analyses of clinical } \\
\text { clearance and cosmetic outcome were carried out by direct examination, dermoscopy, } \\
\text { photographs, as well as by fluorescence diagnosis using a Wood's lamp. Evaluations } \\
\text { were carried out at the different PDT sessions and follow-ups over a 3-year period. } \\
\text { Results: MAL-PDT was safe and highly tolerated. After an average of } 2.6 \text { MAL-PDT } \\
\text { sessions, the overall clearance rate at } 3 \text {-year follow-up was } 96.1 \%(95 \% \text { confidence } \\
\text { interval [CI] } 100 \%-92 \% \text { ) for superficial BCCs and } 95.2 \% \text { ( } 95 \% \text { [CI] } 99 \%-92 \%) \text { for } \\
\text { nodular BCCs after an average of } 2.7 \text { sessions. Minimal side effects such as crushing, } \\
\text { erythema and edema were reported. All BCC lesions showed excellent or good } \\
\text { cosmetic results. } \\
\text { Conclusion: The protocol followed in the present study has proven that MAL-PDT is a } \\
\text { safe and effective treatment for superficial and nodular types of BCC. }\end{array}$ \\
\hline \multirow[t]{3}{*}{ Suggested Reviewers: } & $\begin{array}{l}\text { Eduardo Fonseca, Dr } \\
\text { eduardo.fonseca@usc.es } \\
\text { He is an expert in treating non-melanoma skin cancers with PDT. }\end{array}$ \\
\hline & $\begin{array}{l}\text { Rafael Enríquez de Salamanca, Dr } \\
\text { salamanca@med.ucm.es } \\
\text { He has an extensive research career, with many studies on porphyrias and PDT. }\end{array}$ \\
\hline & $\begin{array}{l}\text { Adolfo Sanz, Dr } \\
\text { adolfosanz22@gmail.com } \\
\text { Dermatologist with a broad research career and knowledge of the interaction of laser } \\
\text { radiation with the skin. }\end{array}$ \\
\hline Response to Reviewers: & $\begin{array}{l}\text { MANUSCRIPT ID PDPDT-D-20-00670 } \\
\text { METHYL AMINOLEVULINATE PHOTODYNAMIC THERAPY AFTER PARTIAL } \\
\text { DEBULKING IN THE TREAMENT OF SUPERFICIAL AND NODULAR BASAL CELL } \\
\text { CARCINOMA: 3-YEARS FOLLOW-UP. } \\
\text { Ron Allison } \\
\text { Editor-in-Chief } \\
\text { Photodiagnosis and Photodynamic Therapy }\end{array}$ \\
\hline
\end{tabular}


We have seriously considered the reviewer comment and the response is addressed below.

Reviewer(s)' Comments to Author:

Reviewer 1:

The authors presented a study, in which MAL-PDT was combined with debulking to treat superficial and nodular BCCs. The follow-up period was long enough to draw conclusions about the long-term efficacy of PDT.

It was a pleasure to read the manuscript. All parts, including Materials and Methods are written clearly and contain every information that are necessary. The Tables are detailed and well-edited, the Figures are representative as well.

The authors want to thank your work by reviewing the article. Your comments generate a lot of gratitude and a desire to continue researching and exploring. Efforts are rewarded.

\section{Reviewer 2:}

This is an interesting manuscript on PDT in BCC treatment after depulking procedures. I think the Authors should report literature data in detail on debulking procedures before PDT application.

Thanks for the comment.

A text detailing debulking procedures before PDT application has been added to the Introduction section (Page 2, lines 6-17).

The authors appreciate the comments by the reviewers to improve the quality of the manuscript.

Sincerely,

Dr. Clara Gómez 
MANUSCRIPT ID PDPDT-D-20-00670

METHYL AMINOLEVULINATE PHOTODYNAMIC THERAPY AFTER

PARTIAL DEBULKING IN THE TREAMENT OF SUPERFICIAL AND NODULAR BASAL CELL CARCINOMA: 3-YEARS FOLLOW-UP.

Ron Allison

Editor-in-Chief

Photodiagnosis and Photodynamic Therapy

We have seriously considered the reviewer comment and the response is addressed below.

Reviewer(s)' Comments to Author:

\section{Reviewer 1:}

The authors presented a study, in which MAL-PDT was combined with debulking to treat superficial and nodular BCCs. The follow-up period was long enough to draw conclusions about the long-term efficacy of PDT.

It was a pleasure to read the manuscript. All parts, including Materials and Methods are written clearly and contain every information that are necessary. The Tables are detailed and well-edited, the Figures are representative as well.

The authors want to thank your work by reviewing the article. Your comments generate a lot of gratitude and a desire to continue researching and exploring. Efforts are rewarded.

\section{Reviewer 2:}

This is an interesting manuscript on PDT in BCC treatment after depulking procedures. I think the Authors should report literature data in detail on debulking procedures before PDT application.

Thanks for the comment.

A text detailing debulking procedures before PDT application has been added to the Introduction section (Page 2, lines 6 - 17).

The authors appreciate the comments by the reviewers to improve the quality of the manuscript.

Sincerely,

Dr. Clara Gómez 


\section{HIGHLIGHTS}

- Partial debulking before MAL/PDT was tested for superficial and nodular BCC.

- The high fluence applied $\left(90 \mathrm{~J} / \mathrm{cm}^{2}\right)$ was effective and safe for all BCC treated.

- Excellent or good cosmesis was observed over 3 years. 


\section{ABSTRACT}

Background: The recently reported increase in the number of basal cell carcinoma (BCC) lesions has prompted the use of minimally invasive therapies. Photodynamic therapy (PDT) is considered to be a good treatment option. The objective of the present work was to analyze the efficacy of methyl aminolevulinate-mediated photodynamic therapy (MAL-PDT) in patients suffering from superficial or nodular BCCs.

Methods: A total of 220 BCC lesions (76 superficial and 144 nodular), clinically diagnosed and confirmed by histopathology analysis, were treated in 174 patients (mean age 72.5 ). Debulking using curettage was performed before two or three MAL-PDT sessions $\left(\lambda=630 \mathrm{~nm} ; 90 \mathrm{~J} / \mathrm{cm}^{2} ; 23 \mathrm{~min}\right)$ at 4 -week intervals. Analyses of clinical clearance and cosmetic outcome were carried out by direct examination, dermoscopy, photographs, as well as by fluorescence diagnosis using a Wood's lamp. Evaluations were carried out at the different PDT sessions and follow-ups over a 3-year period.

Results: MAL-PDT was safe and highly tolerated. After an average of 2.6 MAL-PDT sessions, the overall clearance rate at 3-year follow-up was $96.1 \%$ (95\% confidence interval [CI] 100\%-92\%) for superficial BCCs and 95.2\% (95\% [CI] 99\%-92\%) for nodular BCCs after an average of 2.7 sessions. Minimal side effects such as crushing, erythema and edema were reported. All BCC lesions showed excellent or good cosmetic results.

Conclusion: The protocol followed in the present study has proven that MAL-PDT is a safe and effective treatment for superficial and nodular types of BCC.

Keywords: Photodynamic therapy; methyl aminolevulinate; superficial basal cell carcinoma; nodular basal cell carcinoma. 
Title: Methyl aminolevulinate photodynamic therapy after partial debulking in the treatment of superficial and nodular basal cell carcinoma: 3-years follow-up.

Authors: Clara Gómez ${ }^{1 *}$, Pilar Cobos $^{2}$, Enrique Alberdi ${ }^{2}$

${ }^{1}$ Institute of Physical Chemistry Rocasolano, CSIC, Serrano 119, 28006 Madrid, Spain

${ }^{2}$ Private clinic of Dr. Alberdi, Aviador Zorita 25, 28020 Madrid

\section{Address of authors:}

Clara Gómez (author for correspondence)*:

Institute of Physical Chemistry Rocasolano

Spanish National Research Council, CSIC

C/ Serrano 119, 28006 Madrid

Tel.: +34-91-561-9400 ext.961252

Fax.: +34-91-564-2431

E-mail address: c.gomez@iqfr.csic.es 


\section{INTRODUCTION}

Basal cell carcinoma (BCC) accounts for $80 \%$ of all non-melanoma skin cancers (NMSC) with a steadily increasing incidence, particularly in young individuals [1]. BCC is an epithelial neoplasm that arises from basal cells which constitute the innermost layer of the epidermis. It is a slow-growing dermatological lesion with low metastatic potential [2]. BCC is the most common cancer in individuals with fair skin type (I-II) and a history of cumulative exposure to solar radiation (ultraviolet B) in the first two decades of life. Yet certain categories of patients, such as solid organ transplant recipients and/or chronically immunosuppressed people, are the most frequently affected [3]. It usually appears after age 60, increasing with age [3]. Moreover, if it is not completely removed, BCC can recur in the same place on the skin. Patients who have had basal cell skin cancers are also more likely to develop new cancers elsewhere on the skin.

Classification as a low or high-risk BCC is related to the risk of incomplete excision, recurrence and the rare incidence of metastatic spread. This classification is based on the histological subtype, site and size [4]. Nodular and superficial histological subtypes are considered low-risk lesions, whereas infiltrative basal cell carcinoma is regarded as a high-risk lesion. Yet there are many mixed histological lesions that show an unpredictable behavior [5]. The most common subtypes of BCC are superficial and nodular BCC, being nodular BCC the most common accounting for approximately 57.6-78.7 \% of all BCCs [6].

Surgical intervention of NMSC has a cure rate of $>90 \%$ [7]. Nowadays, multiple therapeutic options (radiotherapy, photodynamic therapy (PDT), topical imiquimod cream, topical 5-fluorouracil (5-FU) and topical ingenol mebutate, intralesional 5-FU, intralesional interferon (IFN)) are available for the treatment of BCC, providing excellent response rates [7]. Patients with BCC frequently present multiple comorbidities, and thus alternative minimally invasive procedures (PDT, 5-FU or imiquimod) are necessary [8].

PDT is recommended for primary superficial and thin low-risk nodular BCC. PDT is best considered for nodular lesions where surgical excision is relatively contraindicated or where patient preference, reflecting past therapy history, comorbidities and/or cosmetic considerations result in willingness to accept a higher risk of recurrence [9]. Higher clearance rates are associated with superficial lesions 
compared with nodular lesions after PDT [10]. Tumors thicker than $2 \mathrm{~mm}$ are less likely to respond to PDT [11]. Nodular BCC shows improved clearance rates if preceded by intense debulking via curettage [12].

The recommended practice according European guidelines for BCC preparation with debulking curettage before PDT is to gently remove overlying crust with a curette in a manner that avoids pain, and minimizes bleeding and thus does not require local anesthesia (preferred for superficial BCC) [9]. In the case of nodular BCC, more significant preparation with debulking of all tumor tissue above the skin level is carried out [13]. New debulking procedures are currently being investigated as laser ablation and electrosurgery $[14,15]$.

Although numerous research studies and clinical data have shown the efficacy of PDT in BCC, the objective of this 3-year prospective study was to analyze the efficacy of methyl aminolevulinate MALPDT with prior debulking via curettage on a wide range of superficial and nodular BCC lesions of various sizes and locations.

\section{METHODS}

Patients

We conducted a retrospective study with 174 adult patients suffering from superficial $\mathrm{BCC}(\mathrm{n}=56,32 \%)$ and nodular BCC $(\mathrm{n}=118,68 \%)$ treated with MAL-PDT in a private clinic between January 2014 and December 2019. Lesions were clinically diagnosed and assisted by dermoscopy and histology if needed. Patients' age ranged from 33 to 100 years, with generally one lesion located in different parts of the body (mainly on the trunk for superficial BCC and head for nodular BCC). Lesions were measured at baseline with a maximum diameter of $5 \mathrm{~cm}$ for superficial subtypes and $2 \mathrm{~cm}$ for nodular ones. Baseline characteristics of the sample population are shown in Table 1 and Table 2.

The study was conducted in compliance with Good Clinical Practice and local regulatory requirements. All patients provided written informed consent before inclusion into the study.

Restrictive inclusion/exclusion criteria were followed. Inclusion criteria: $>18$ years of age with a clinical diagnosis of primary superficial or nodular BCC, suitable for simple surgical excision. Exclusion criteria: recurrent $\mathrm{BCC}$, active systemic infectious disease, more than six eligible lesions, lesions located on 
severely sun-damaged skin where surgery may not be suitable due to the frequent occurrence of other BCCs in the same area, lesions located close to or involving a scar of squamous cell carcinoma, as well as pigmented, morpheaform or infiltrative lesions on the treated area. Patients excluded from the study included those at risk in terms of precautions, warnings and contraindications as indicated in the package insert for MAL-PDT (porphyria), as well as women who were pregnant or breastfeeding.

Concurrent use of cryotherapy, surgery, 5-fluorouracil, radiotherapy, aminolevulinate-based PDT, imiquimod or electrodesiccation was prohibited.

In addition, patients were selected for PDT when attending to lesions with difficult treatment, avoiding an invasive surgical option as treatment for cosmetic reasons, in the presence of other comorbidities that could cause complications with general anesthesia, as well as patients' request for minimally invasive procedures.

\section{Treatment}

Immediately prior to PDT, both superficial and nodular BCC lesions were prepared by gentle curettage to remove scales and crusts from the surface and to facilitate cream and light penetration. A debulking procedure (more significant for nodular BCCs) was performed by removing only the visible part of the tumors using a small surgical curette (House, $3 \pm 9$ French, Elcon, Tuttlingen, Germany). This intratumoral curettage spared the underlying dermis and adjacent normal skin. At the most, only a minimum of bleeding took place. The debulking procedure was performed without a topical agent to avoid loss of absorption of MAL and, thus, loss of the photodynamic effect.

Next, 16\% MAL cream (Metvix ${ }^{\circledR}$, Galderma, Italy/Spain) was applied over the lesion along with a $1 \mathrm{~cm}$ margin around its visible edge. The area was them covered with an occlusive bandaje for $3 \mathrm{~h}$ and photoactivated using a red light-emitting diode (LED) lamp at a peak wavelength of $630 \mathrm{~nm}$; $90 \mathrm{~J} / \mathrm{cm}^{2}$, $23 \mathrm{~min}$ (Aktilite, Galderma, Italy). After treatment, antibiotic ointment and light dressings were applied to the lesion. Additionally, one or two extra curettage+PDT sessions were performed after a 4-week interval depending on the stage of the healing process. Fluorescence diagnosis with a Wood's lamp was done to help delineate the lesions. Figure 1 schematically shows the study design. Patient, operator, and assistants wore protective eyewear during the application of laser radiation. 
Patients were advised to limit or completely avoid light/sun exposure for approximately 24-48 h after treatment. After this time interval, they were also advised to apply sunscreen cream SPF 50+ during the entire duration of the study and only use an emollient soap.

\section{Follow-up and tumor response}

Clinical variables such as sex, age, tumor location, number of lesions and size together with procedural variables (number of PDT sessions), local skin reactions and cosmetic outcome were evaluated to monitor any potential association with treatment response (Table 1 y 2 ).

Immediately after each PDT session, the patients were checked for possible side effects or complications: pain, erythema, edema, crust formation, hyper- or hypopigmentation, permanent hair loss or allergic contact dermatitis.

All lesions were photographed at baseline, each PDT session, 3, 6-month and 1, 2 and 3-year follow-ups to further evaluate the clinical response and cosmetic outcome. Both overview and close-up photographs were taken. For the close-up images, a ruler was taped next to the lesion to have a sense of its size. Treatment failure before the 3-month follow-up was controlled and recurrences during the 3-years followup period were identified via inspection, dermoscopy and fluorescence diagnosis using a Wood's lamp (Figure 1).

Overall cosmetic outcome was assessed over the course of 3 years (Figure 1) with regard to the occurrence of the following signs: scarring, atrophy, depigmentation, redness and fibrosis. Cosmetic outcome was rated as poor, fair, good or excellent [16].

\section{Statistical analysis}

Clinical and pathological characteristics were summarized using descriptive statistics. The results are expressed as mean or median $\pm \mathrm{SD}$ and range for continuous data, and as percentages and range of confidence for categorical data.

\section{RESULTS}

A total of $220 \mathrm{BCC}$ lesions (174 patients) were treated. In the case of superficial BCC subtypes, 76 lesions with a mean diameter of $18.5 \pm 11.9 \mathrm{~mm}$ were treated in 56 patients $(50 \%$ men; $50 \%$ women) with a mean age of $71.1 \pm 12.9$ years. In the case of nodular BCC subtypes, 144 lesions with a mean diameter of 
$8.9 \pm 5.1 \mathrm{~mm}$ were treated in 118 patients (52\% men; $48 \%$ women) with a mean age of $73.8 \pm 12.7$ years (Table 1). Clinical images and those obtained by Wood's lamp examinations over the course of the study are shown in Figs. 2 and 3.

Nodular subtype predominated on the head (108/144) and superficial subtype on the trunk (31/76). Nodular type predominated on the face in women (60/108) vs. (40/108) in men, whereas they predominate on the trunk in men (11/13) vs. (2/13) in women (Table 2). Similar distribution between men and women was observed for superficial subtype (Table 2).

MAL-PDT was well tolerated. Minimal side effects included crusting due to the debulking process, perilesional edema, erythema. Mild pain was common during PDT illumination. After illumination had ceased, the pain intensity immediately lessened (Table 1). Clinical improvement was assessed at each follow-up visit. Clinical response to therapy was evaluated according to Rhodes and colleagues [17], setting the absence of a clinically evident lesion at the treatment site as complete response (CR) and a marked reduction $(>50 \%)$ in tumor size as partial response (PR). No response (NR) was defined as insignificant reduction $(<50 \%)$ in tumor size. Results showed that $97.4 \%(95 \%$ CI $100 \%-95 \%)$ of the superficial BCC lesions achieved CR in the first year and 97.2\% (95\% CI 100\%-95\%) in the case of the nodular BCC lesions. At 3-year follow up, results showed $96.1 \%$ (95\%CI 100\%-92\%) for superficial BCCs and $95.2 \%$ (95\% CI 99\%-92\%) for nodular BCCs. The mean number of sessions needed to achieve CR was 2.6 for superficial BCC and 2.7 for nodular BCC. Figures 2 and 3 show the CR achieved in a superficial and a nodular subtype respectively at 1-year follow-up.

As for superficial BCC lesions, 2 early failures were observed on the scalp and 1 recurrence on the forehead at 3-year follow-up. In the case of nodular BCC lesions, 3 early failures were observed on the nose, 1 recurrence on the cheek at 1-year follow-up, 2 recurrences on the nose at 3-year follow-up and also 1 on the temple at 3-year follow-up (Table 3).

Cosmetic outcomes of lesions showing CR were classified as excellent (no scarring, atrophy or induration, and slight or no redness or change in pigmentation compared with adjacent skin) in $90 \%$ of the superficial BCC lesions and $70 \%$ of the nodular BCC lesions; good (no scarring, atrophy or induration, and moderate redness or increased pigmentation compared with adjacent skin) in $10 \%$ of the superficial BCC lesions and 30\% of the nodular BCC lesions. No lesions showed fair or poor outcome (Table 1). 


\section{DISCUSSION}

PDT is an effective treatment option for BCC. Numerous retrospective, randomized and comparative studies support the efficacy of PDT in the treatment of BCC. Cure rates range from $87 \%$ to $100 \%$ for superficial BCC and $10 \%$ to $70 \%$ for nodular BCC $[17,18]$. From these data, it can be deduced that surgery is still the most effective treatment for nodular BCC, but PDT shows a better cosmetic outcome.

It is difficult to compare the results of a new PDT study with those obtained in previous published research for different reasons: the population sample is usually different in characteristics and size; PDT protocols are not standardized, different pre-treatments of the lesions, different type of photosensitizer (PS), different drug-to-light intervals, different irradiation procedures, and endpoints and follow-up criteria which are often not well defined [19]. The usual MAL-PDT protocol for the treatment of BCC lesions is 1 cycle consisting of 2 sessions at $37 \mathrm{~J} / \mathrm{cm}^{2}$ spaced 1 week apart. Another session is performed after 1 month if necessary. Success rates for nodular BCC are lower in those studies in which no prior debulking was performed [19]. Differences in light penetration within the tumor nodules can explain the different response in superficial and nodular BCC. The novelty introduced in the protocol followed in our study lies in the use of debulking via curettage before two or generally three PDT sessions with an increased fluence of $90 \mathrm{~J} / \mathrm{cm}^{2}$ spaced one month apart, resulting in a similar cure rate for superficial types of BCC $(96 \%)$ as reported in previous studies [17,18], yet increased in the case of nodular types $(95 \%)$ $[17,18]$.

The results of the present study corroborate those of other recent research on the real efficacy of MALPDT in superficial BCC. They also show greater efficacy of MAL-PDT in nodular BCCs compared to previous published studies. This was probably due to the caution exercised in the assessment of the location and size of the lesions, appropriate debulking and the application of a higher fluence $\left(90 \mathrm{~J} / \mathrm{cm}^{2}\right.$ vs. $37 \mathrm{~J} / \mathrm{cm}^{2}$ ). Ramirez et al. demonstrated that previous professional experience in the management of PDT for BCC treatment improves the therapeutic outcome. This experience results in an improved selection of the lesions, and also in a better ability to perform proper lesion curettage for PDT [20].

Current long term follow-up data demonstrate that most BCC recurrences after PDT appear after the first 2 years of treatment [13]. Our study reports very low rates of early failure and recurrence. More research is needed to draw conclusions about failure or recurrence. The efficacy of PDT is inversely related to the thickening of the lesion: the greater the thickness of the lesion, the lesser the penetration of the luminous 
radiation or PS through the skin. Other factors such as the age of the patient and the tumor's size and location also play a role.

Molecular or genetic factors can also modify or condition the response to PDT [21]. Failures and recurrences were clinically analyzed and by the use of the Wood's lamp. Fluorescence evaluation avoids the need to perform routine post-treatment biopsies. Fluorescence is less sensitive than histological analysis but it has the advantage of avoiding an invasive procedure on the patient. It evaluates the entire area of the lesion.

To improve treatment outcomes, PDT can also be used in combination with radiation therapy, curettage, diclofenac, 5-fluorouracil and imiquimod [22]. Given that the limiting factor for PDT is its inability to penetrate to depths beyond $2 \mathrm{~mm}$, the use of ablative Er:YAG and $\mathrm{CO}_{2}$ lasers to reduce tumor depth to less than $2 \mathrm{~mm}$ with subsequent PDT for the treatment of BCC could be considered [23, 24]. This pretreatment of the lesion lets us get around the natural impermeability of the skin that constitutes a barrier to the diffusion of PS into deeper layers, thus allowing a better PS absorption. This could have a significant impact on the clearance rate [14].

Introducing variables in the MAL-PDT protocol causes a different response. A comparison between randomized trials with a very similar superficial BCC cohort suggests that more than two PDT sessions could achieve better therapeutic results [25]. Recent studies show the application of a fractionated PDT in a single visit (20\% MAL cream with occlusive dressing during $3 \mathrm{~h}$ followed by 20 min of LED light interval $\lambda=630 \mathrm{~nm}, 125 \mathrm{~mW} / \mathrm{cm}^{2}$ ). Next, MAL cream reapplication with occlusive dressing during 90 min followed by $20 \mathrm{~min}$ of LED light interval $\lambda=630 \mathrm{~nm}, 125 \mathrm{~mW} / \mathrm{cm}^{2}$ [26]. In general, studies on fractionated PDT report higher tissue phototoxicity because the time gap between irradiations allows the resynthesis of PpIX [27]. Another new PDT procedure is daylight-PDT without occlusion where natural light is used instead of an artificial light source, thus reducing the time the patient spends in the clinic, as well as the pain intensity due to the continuous production and photoactivation of small amounts of PpIX [28]. Daylight-PDT has proven to be as effective as conventional PDT in the treatment of superficial and small nodular BCC. The cosmetic outcome was also similar to that observed with conventional PDT [29].

The combined excellent/good cosmetic outcome rates here obtained were consistent with previous studies of MAL/PDT for BCCs $[30,31]$. MAL-PDT is a therapeutic modality particularly suitable for the 
treatment of BCC. Its excellent cosmesis has been widely reported [30]. This is of great interest for the treatment of extensive and multiple lesions [32] or when these are located on areas prone to hypertrophic scarring and/or keloids such as the trunk and legs [33]. There is no long-term or cumulative toxicity of MAL-PDT and no side effects or scarring in case of retreatment for recurrence. For all these reasons, this noninvasive treatment is especially indicated in young patients to avoid the potential psychological impact of poor healing and cosmesis. It is also suitable for people with comorbidity and people unable to tolerate the inflammatory side effects of topical preparations.

\section{Conclusions}

The results of the present study confirm that PDT is an attractive treatment option for superficial and nodular BCC, based on its favorable efficacy and low side-effect profile. MAL-PDT preserves the skin and shows favorable cosmetic results. Further identification of new PSs and new methods for increasing their penetrance in the tumors, as well as the design of original therapeutic protocols are currently under intense investigation to address the optimal treatment guidelines for BCCs.

\section{Financial disclosure/Acknowledgements}

This research was supported by a grant from the Eugenio Rodríguez Pascual Foundation (Madrid, Spain) and by the Spanish Research Project MINECO (Ref.: MAT 2017-83856-C3). The author have no other relevant affiliation or financial involvement with any organization or entity with a financial interest in or financial conflict with the subject matter or materials discussed in the manuscript apart from those disclosed. 


\section{REFERENCES}

[1] A. Lomas, J. Leonardi-Bee, F. Bath-Hextall, A systematic review of worldwide incidence of nonmelanoma skin cancer, Br. J. Dermatol. 166 (2012) 1069-1080.

[2] K. Tanese, Diagnosis and Management of Basal Cell Carcinoma, Curr. Treat. Options Oncol. 20(2) (2019) 13. doi: 10.1007/s11864-019-0610-0.

[3] V.P. Chinem, H.A. Miot, Epidemiology of basal cell carcinoma, An. Bras. Dermatol. 86(2) (2011) 292-305.

[4] M. Trakatelli, C. Morton, E. Nagore, C. Ulrich, V. Del Marmol, K. Peris, N. Basset-Seguin; BCC subcommittee of the Guidelines Committee of the European Dermatology Forum, Update of the European guidelines for basal cell carcinoma management, Eur. J. Dermatol, 24(3) (2014) 312-329.

[5] A. Ghanadan, A. Abbasi, M. Rabet, P. Abdollahi, M. Abbasi, Characteristics of mixed type basal cell carcinoma in comparison to other BCC subtypes, Indian J. Dermatol. 59(1) (2014) 56-59.

[6] A.W. Kopf, Computer analysis of 3531 basal cell carcinomas of the skin, J. Dermatol. 6(5) (1979) 267-281.

[7] C.M. Clark, M. Furniss, J.M. Mackay-Wiggan, Basal cell carcinoma: an evidence-based treatment update, Am. J. Clin. Dermatol. 15(3) (2014) 197-216.

[8] L.A. Kwasniak, J. García-Zuazaga, Basal cell carcinoma: evidence-based medicine and review of treatment modalities, Int. J. Dermatol. 50(6) (2011) 645-658.

[9] C.A. Morton, R.M. Szeimies, A. Sidoroff, L.R. Braathen, European guidelines for topical photodynamic therapy part 1: treatment delivery and current indications - actinic keratoses, Bowen's disease, basal cell carcinoma, J. Eur. Acad. Dermatol. Venereol. 27(5) (2013) 536-544.

[10] R. Ceović, M. Petković, Z.B. Mokos, K. Kostović, Nonsurgical treatment of nonmelanoma skin cancer in the mature patient, Clin. Dermatol. 36(2) (2018) 177-187. 
[11] C.A. Morton, R.M. Mackie, C. Whitehurst, J.V. Moore, J.H. McColl, Photodynamic therapy for basal cell carcinoma: effect of tumor thickness and duration of photosensitizer application on response, Arch. Dermatol. 134(2) (1998) 248-249.

[12] P. Savoia, T. Deboli, A. Previgliano, P. Broganelli, Uselfulness of photodynamic therapy as a possible therapeutic alternative in the treatment of basal cell carcinoma, Int. J. Mol. Sci. 16(10) (2015) $23300-23317$.

[13] M.C. Fargnoli, K. Peris, Photodynamic Therapy for basal cell carcinoma, Future Oncol. 11(22) (2015) 2991-2996.

[14] J. Lippert, R. Smucler, M. Vlk, Fractional carbon dioxide laser improves nodular basal cell carcinoma treatment with photodynamic therapy with methyl 5-aminolevulinate, Dermatol. Surg. 39 (8) (2013) 1202-1208.

[15] F. de A. Rego Filho, R.A. Caldas, C. Kurachi, V.S. Bagnato, M.T. de Araujo. Possibility for the conjugated use of photodynamic therapy and electrosurgical devices. PLoS One 10(8) (2015) e0136194.

[16] N.A. Samy, M.M. Salah, M.F. Ali, A.M. Sadek, Effect of methylene blue-mediated photodynamic therapy for treatment of basal cell carcinoma, Lasers Med. Sci. 30(1) (2015) 109-115.

[17] L.E. Rhodes, M.A. de Rie, R. Leifsdottir, R.C. Yu, I. Bachmann, V. Goulden, G.A. Wong, M.A. Richard, A. Anstey, P. Wolf, Five-year follow-up of a randomized, prospective trial of topical methyl aminolevulinate photodynamic therapy vs surgery for nodular basal cell carcinoma, Arch. Dermatol. 143(9) (2007) 1131-1136.

[18] T. Surrenti, L. De Angelis, A. Di Cesare, M.C. Fargnoli, K. Peris, Efficacy of photodynamic therapy with methyl aminolevulinate in the treatment of superficial and nodular basal cell carcinoma: an openlabel trial, Eur. J. Dermatol. 17(5) (2007) 412-415.

[19] F. Fantini, A. Greco, C. Del Giovane, A.M. Cesinaro, M. Venturini, C. Zane, T. Surrenti, K. Peris, P.G. Calzavara-Pinton, Photodynamic therapy for basal cell carcinoma: clinical and pathological determinants of response, J. Eur. Acad. Dermatol. Venereol. 25(8) (2011) 896-901.

[20] D.P. Ramirez, C. Kurachi, N.M. Inada, L.T. Moriyama, A.G. Salvio, J.D. Vollet Filho, L. Pires, H.H. Buzzá, C.T. Teles de Andrade, C. Greco, V.S. Bagnato, Experience and BCC subtypes as determinants of 
MAL-PDT response: preliminary results of a national Brazilian project, Photodiagnosis Photodyn. Ther. 11(1) (2014) 22-26.

[21] S.R. Lucena, A. Zamarrón, E. Carrasco, M.A. Marigil, M. Mascaraque, M. Fernández-Guarino, Y. Gilaberte, S. González, A. Juarranz, Characterization of resistance mechanisms developed by basal cell carcinoma cells in response to repeated cycles of Photodynamic Therapy, Sci. Rep. 9(1) (2019) 4835 doi: 10.1038/s41598-019-41313-y.

[22] S.R. Lucena, N. Salazar, T. Gracia-Cazaña, A. Zamarrón, S. González, A. Juarranz, Y. Gilaberte, Combined treatments with photodynamic therapy for non-melanom skin cancer, Int. J. Mol. Sci. 16(10) (2015) 25912-25933.

[23] R. Smucler, M. Vlk, Combination of Er:YAG laser and photodynamic therapy in the treatment of nodular basal cell carcinoma, Lasers Surg. Med. 40(2) (2008) 153-158.

[24] I.S. Whitaker, K. Shokrollahi, W. James, A. Mishra, P. Lohana, M.C. Murison, Combined CO(2) laser with photodynamic therapy for the treatment of nodular basal cell carcinomas, Am. Plast. Surg. 59(5) (2007) 484-488.

[25] I.O. de Albuquerque, J Nunes, J.P. Figueiró Longo, L.A. Muehlmann, R. B. Azevedo, Photodynamic therapy in superficial basal cell carcinoma treatment, Photodiagnosis Photodyn. Ther. 27 (2019): 428432.

[26] D.P. Ramirez, L.T. Moriyama, E.R. de Oliveira, N.M. Inada, V.S. Bagnato, C. Kurachi, A.G. Salvio, Single visit PDT for basal cell carcinoma - A new therapeutic protocol, Photodiagnosis Photodyn. Ther. 26 (2019) 375-382.

[27] S. Mallidi, S. Anbil, A.L. Bulin, G. Obaid, M. Ichikawa, T. Hasan, Beyond the barriers of light penetration: strategies, perspectives and possibilities for photodynamic therapy, Theranostic 6(13) (2016) 2458-2487.

[28] S.R. Wiegell, M. Haedersdal, P.A. Philipsen, P. Eriksen, C.D. Enk, H.C. Wulf, Continuous activation of PpIX by daylight is as effective and less painful that conventional photodynamic therapy for actinic keratosis-a randomized, controlled, single-blinded study, Br. J. Dermatol. 158(4) (2008) 740-746. 
[29] S.R. Wiegell, V. Skødt, H.C. Wulf, Daylight-mediated photodynamic therapy of basal cell carcinomas-an explorative study, J. Eur. Acad. Dermatol. Venereol. 28 (2) (2014) 169-175.

[30] R.M. Szeimies, S. Ibbotson, D.F. Murrell, D. Rubel, Y. Frambach, D. de Berker, R. Dummer, N. Kerrouche, H. Villemagne; Excilight Study Group, A clinical study comparing methyl aminolevulinate photodynamic therapy and surgery in small superficial basal cell carcinoma $(8-20 \mathrm{~mm})$, with a 12-month follow-up, J. Eur. Acad. Dermatol. Venereol. 22(11) (2008) 1302-1311.

[31] S.H. Choi, K.H. Kim, K.H. Song. Er:YAG ablative fractional laser-primed photodynamic therapy with methyl aminolevulinate as an alternative treatment option for patients with thin nodular basal cell carcinoma: 12-month follow-up results of a randomized, prospective, comparative trial. J. Eur. Acad. Dermatol. Venereol. 30 (5) (2016) 783-788.

[32] C. Vinciullo, T. Elliott, D. Francis, K. Gebauer, L. Spelman, R. Nguyen, W. Weightman, A. Sheridan, C. Reid, D. Czarnecki, D. Murrell, Photodynamic therapy with topical methyl aminolaevulinate for 'difficult-to-treat' basal cell carcinoma, Br. J. Dermatol. 152 (4) (2005) 765-772.

[33] B.A. Raasch, P.G. Buettner, C. Garbe, Basal cell carcinoma, histological classification and body-site distribution, Br. J. Dermatol. 155(2) (2006) 401-407. 
Table 1.- Baseline demographics of recruited patients. $(\mathrm{nBCC}=$ nodular $\mathrm{BCC}$; $\mathrm{sBCC}=$ superficial $\mathrm{BCC}$; $\emptyset=$ diameter of lesion)

\begin{tabular}{|c|c|c|}
\hline & $\mathrm{sBCC}$ & $\mathrm{nBCC}$ \\
\hline $\begin{array}{l}\text { Subjects } \\
\text { Male }[\mathrm{n}(\%)] \\
\text { Female }[\mathrm{n}(\%)] \\
\text { Age [mean } \pm(\mathrm{SD})] ; \text { range; median }\end{array}$ & $\begin{array}{l}56 \\
28(50 \%) \\
28(50 \%) \\
71.1 \pm 12.9 ;[34,99] ; 69\end{array}$ & $\begin{array}{l}118 \\
61(52 \%) \\
57(48 \%) \\
73.8 \pm 12.7 ;[33,100] ; 75.5\end{array}$ \\
\hline $\begin{array}{l}\text { Total lesions } \\
\varnothing[\text { mean } \pm(\mathrm{SD})] ; \text { range; median } \\
\text { Lesions/patient } \\
1 \\
2 \\
3 \\
4 \\
5 \\
6 \\
\text { Mean lesions/patient }\end{array}$ & $\begin{array}{l}76 \\
18.5 \pm 11.9 \mathrm{~mm} ;[50,5] ; 15 \\
46(82.1 \%) \\
7(12.5 \%) \\
0(0 \%) \\
1(1.8 \%) \\
0(0 \%) \\
2(3.6 \%) \\
1.36\end{array}$ & $\begin{array}{l}144 \\
8.9 \pm 5.1 \mathrm{~mm} ;[20,3] ; 10 \\
105(88.9 \%) \\
10(8.5 \%) \\
1(0.8 \%) \\
4(3.4 \%) \\
0(0 \%) \\
0(0 \%) \\
1.22\end{array}$ \\
\hline $\begin{array}{l}\text { Location of lesions } \\
\text { Face } \\
\quad \text { Forehead } \\
\text { Temple } \\
\text { Nose } \\
\text { Cheek } \\
\quad \text { Perioral/Nasolabial } \\
\text { Ear } \\
\text { Scalp } \\
\text { Neck } \\
\text { Trunk } \\
\text { Arms } \\
\text { Legs }\end{array}$ & $\begin{array}{l}25(32.9 \%) \\
\quad 6 \\
2 \\
6 \\
7 \\
2 \\
2 \\
5(6.6 \%) \\
4(5.3 \%) \\
31(40.8 \%) \\
5(6.6 \%) \\
6(7.9 \%)\end{array}$ & $\begin{array}{l}108(75 \%) \\
36 \\
5 \\
38 \\
17 \\
4 \\
8 \\
14(9.7 \%) \\
4(2.8 \%) \\
13(9 \%) \\
3(2.1 \%) \\
2(1.4 \%)\end{array}$ \\
\hline $\begin{array}{l}\text { Number of sessions applied } \\
1 \\
2 \\
3 \\
4 \\
5 \\
\text { Mean number of sessions }\end{array}$ & $\begin{array}{l}0 \\
16 \\
59 \\
1 \\
0 \\
2.6\end{array}$ & $\begin{array}{l}4 \\
27 \\
110 \\
3 \\
0 \\
2.7\end{array}$ \\
\hline $\begin{array}{l}\text { Complete response } \\
\text { 1-year follow-up } \\
\text { 2-year follow-up } \\
\text { 3-year follow-up }\end{array}$ & $\begin{array}{l}73 / 76 \\
74(97.4 \%) \\
74(97.4 \%) \\
73(96.1 \%)\end{array}$ & $\begin{array}{l}137 / 144 \\
140(97.2 \%) \\
140(97.2 \%) \\
137(95.2 \%)\end{array}$ \\
\hline $\begin{array}{l}\text { Cosmetic outcomes } \\
\text { Excellent } \\
\text { Good }\end{array}$ & $\begin{array}{l}68(90 \%) \\
8(10 \%)\end{array}$ & $\begin{array}{l}101(70 \%) \\
43(30 \%)\end{array}$ \\
\hline $\begin{array}{l}\text { Side effects } \\
\text { Erythema perilesional } \\
\text { Crusting } \\
\text { Edema perilesional } \\
\text { Mild pain }\end{array}$ & $\begin{array}{l}62(81.5 \%) \\
76(100 \%) \\
47(61.8 \%) \\
76(100 \%)\end{array}$ & $\begin{array}{l}88(61.1 \%) \\
144(100 \%) \\
117(81.3 \%) \\
144(100 \%)\end{array}$ \\
\hline
\end{tabular}


Table 2.- Anatomic distribution of each subtype of BCC according to gender ( $\mathrm{n}=$ number of patients; $(\%)$ $=$ percentage of patients; $\mathrm{BCC}$ : superficial BCC; nBCC: nodular BCC)

\begin{tabular}{|l|l|l|l|l|}
\cline { 2 - 5 } \multicolumn{1}{c|}{} & \multicolumn{2}{c|}{ sBCC } & \multicolumn{2}{c|}{ nBCC } \\
\hline Location of lesions & Male [n(\%)] & Female [n (\%)] & Male [n (\%)] & Female [n (\%)] \\
Face & $14(18.4 \%)$ & $11(14.5 \%)$ & $48(33.3 \%)$ & $60(41.7 \%)$ \\
Scalp & $3(3.9 \%)$ & $2(2.6 \%)$ & $11(7.6 \%)$ & $3(2.1 \%)$ \\
Neck & $3(3.9 \%)$ & $1(1.3 \%)$ & $3(2.1 \%)$ & $1(0.7 \%)$ \\
Trunk & $17(22.4 \%)$ & $14(18.4 \%)$ & $11(7.6 \%)$ & $2(1.4 \%)$ \\
Arms & $3(3.9 \%)$ & $2(2.6 \%)$ & $3(2.1 \%)$ & $0(0 \%)$ \\
Legs & $3(3.9 \%)$ & $3(3.9 \%)$ & $2(1.4 \%)$ & $0(0 \%)$ \\
& & & & \\
\hline
\end{tabular}


Table 3.- Success at 3 years ( $\mathrm{n}=$ number of lesions; $\mathrm{EF}=$ early failure; $\mathrm{R}=$ recurrence; $\mathrm{CR}=$ complete response)

\begin{tabular}{|l|c|l|l|l|l|l|l|l|}
\cline { 2 - 8 } \multicolumn{1}{c|}{} & \multicolumn{3}{c|}{ sBCC } & \multicolumn{3}{c|}{ nBCC } \\
\hline & Lesions(n) & EF(n) & R(n) & CR(n) & Lesions(n) & EF(n) & R(n) & CR(n) \\
\hline Forehead & 6 & 0 & 1 & 5 & 36 & 0 & 0 & 36 \\
Temple & 2 & 0 & 0 & 2 & 5 & 0 & 1 & 4 \\
Nose & 6 & 0 & 0 & 6 & 38 & 3 & 2 & 33 \\
Cheek & 7 & 0 & 0 & 7 & 17 & 0 & 1 & 16 \\
Perioral/Nasolabial & 2 & 0 & 0 & 2 & 4 & 0 & 0 & 4 \\
Ear & 2 & 0 & 0 & 2 & 8 & 0 & 0 & 8 \\
Scalp & 5 & 2 & 0 & 3 & 14 & 0 & 0 & 14 \\
Neck & 4 & 0 & 0 & 4 & 4 & 0 & 0 & 4 \\
Trunk & 31 & 0 & 0 & 31 & 13 & 0 & 0 & 13 \\
Arms & 5 & 0 & 0 & 5 & 3 & 0 & 0 & 3 \\
Legs & 6 & 0 & 0 & 6 & 2 & 0 & 0 & 2 \\
\hline TOTAL & 76 & 2 & 1 & 73 & 144 & 3 & 4 & 137 \\
\hline
\end{tabular}




\section{Figure captions}

Figure 1. - Study design overview.

Figure 2. - 66-year-old female. (A) Superficial $50 \mathrm{~mm}$ in diameter BCC lesion located on the back before treatment, (B) delineated lesion via a Wood's lamp before PDT, (C) CR at 12-month follow-up after 4 sessions of MAL-PDT.

Figure 3. - 82-year-old male. (A) Nodular $8 \mathrm{~mm}$ in diameter BCC lesion located on the neck before treatment, (B) delineated lesion via a Wood's lamp before PDT, (C) CR at 12-month follow-up after 3 sessions of MAL-PDT. 


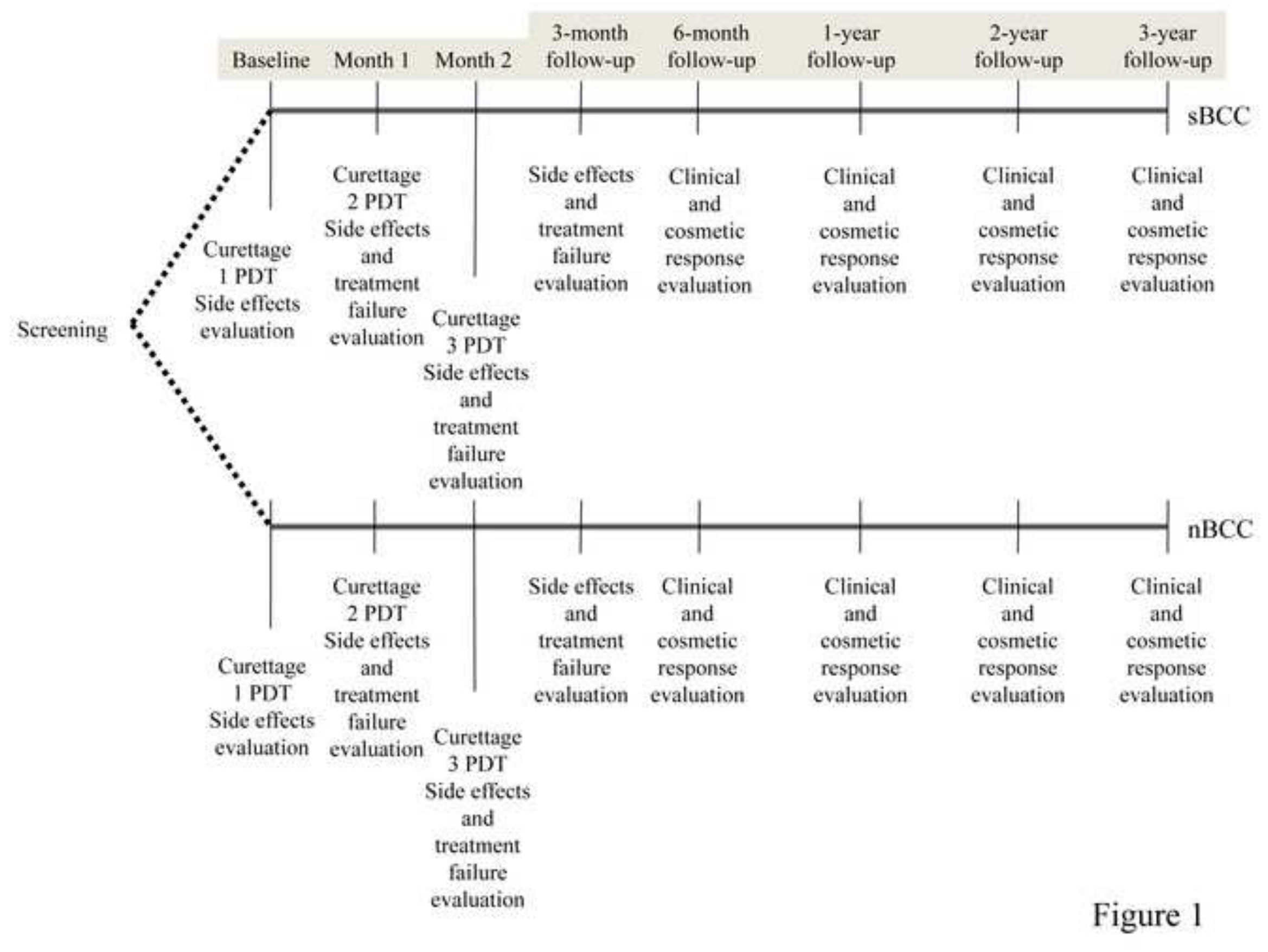


Click here to access/download;Figure;Figure 2.tif $\underline{\underline{ }}$
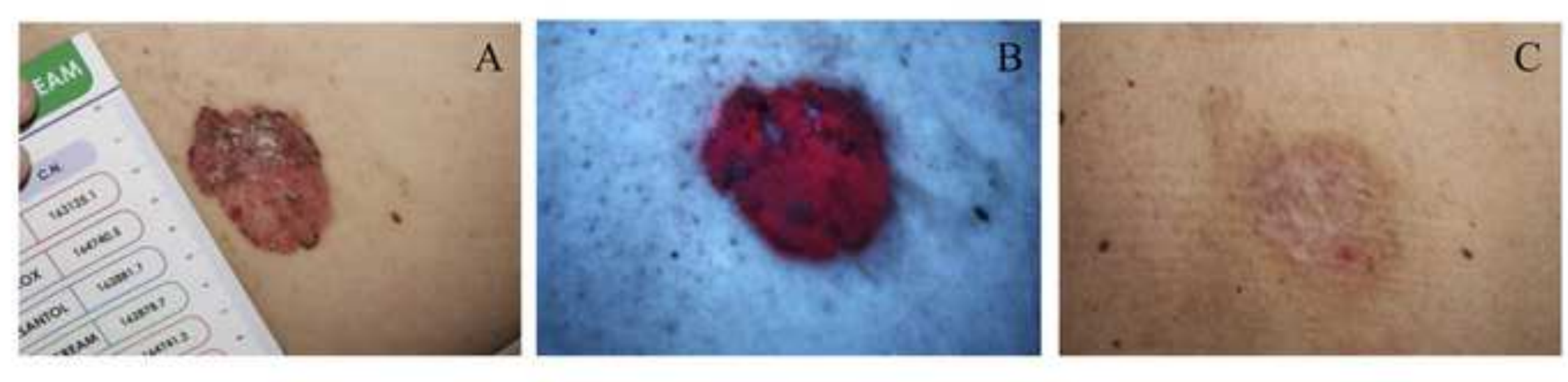

Fure 2

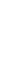

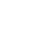

\section{Figure 2}
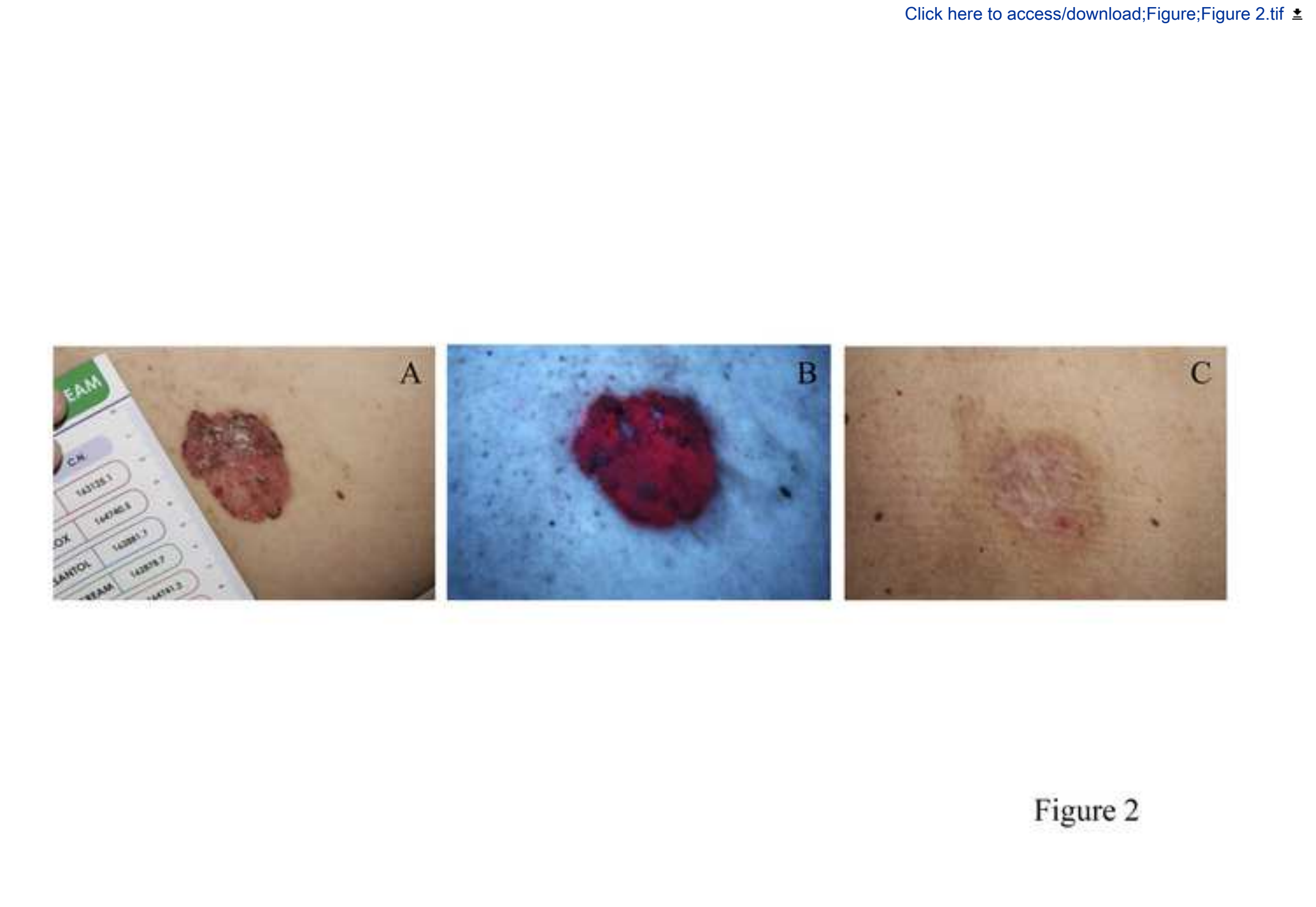

C

C

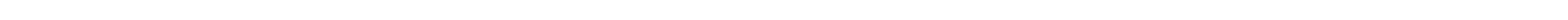



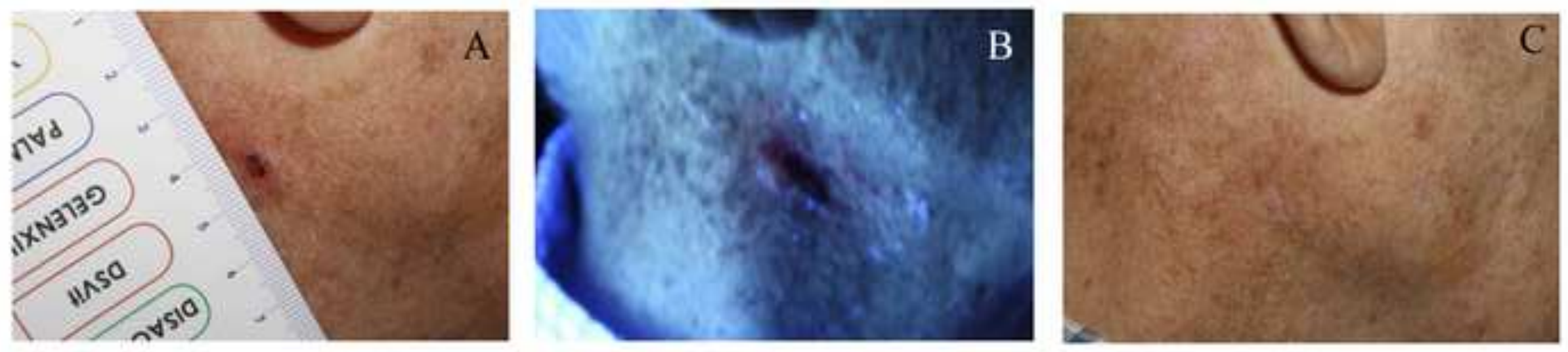

Figure 3 